\title{
Mass Spectrometry in Wastewater-Based Epidemiology for the Determination of Small and Large Molecules as Biomarkers of Exposure: Toward a Global View of Environment and Human Health under the COVID-19 Outbreak
}

\author{
Yolanda Picó* and Damià Barceló*
}

Cite This: ACS Omega 2021, 6, 30865-30872

ABSTRACT: Wastewater-based epidemiology (WBE) estimates collective consumption or exposure to chemicals or pathogens by monitoring the substances excreted in the population's wastewater. Advances in mass spectrometry (MS) and the application of some clinical diagnostic tools and proteomics to wastewater fingerprinting have been linked to the discovery of new biomarkers and indicators of population health and are broadening the scope of WBE that nowadays cover not only small molecule biomarkers but also genetic biomarkers, large molecules, viruses, infection diseases, resistance, etc. This mini-review highlights recent $\mathrm{WBE}$ advances using $\mathrm{MS}$ and how this progress can create a fingerprint of a city's health hazards, habits, and lifestyle, which is gaining in public health emphasis.

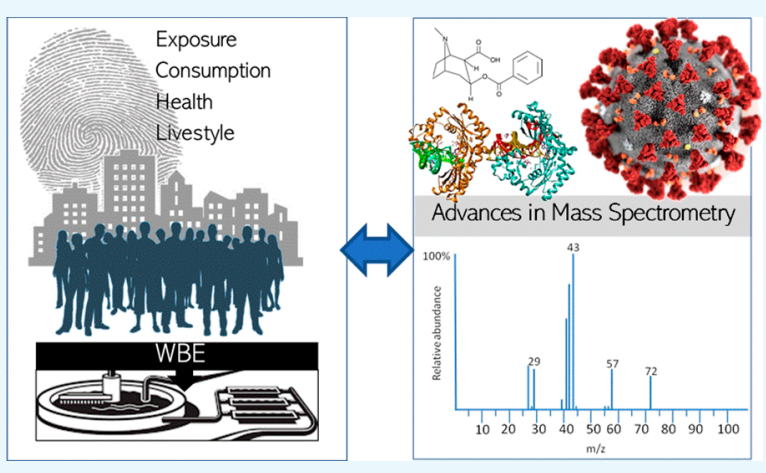

\section{INTRODUCTION}

Wastewater-based epidemiology (WBE) has already shown to be an innovative and promising tool for the estimation of some unhealthy or poorly confessable habits at the community level, such as drug, alcohol, and tobacco use. ${ }^{1}$ Figure 1 outlines the classical workflow to estimate illicit drug consumption. Drugs or their human metabolites are determined by liquid chromatography-mass spectrometry (LC-MS). Their concentration is combined with a few additional pieces of information to estimate consumption. In fact, the WBE evolution has been closely linked to instrumental development, especially of mass spectrometry (MS). ${ }^{2}$

Growing research attention has been paid to WBE that could now be regarded as a means of measuring a community's unique, collective health status, akin to a profile, signature, or fingerprint of overall health. ${ }^{3}$ It overcomes some of the limitations of conventional biomonitoring, which can only collect data from individuals and involve high costs and considerable resources and cannot provide results in near real-time. Given this, WBE has been developed steadily over the last 15 years. ${ }^{4}$ Most of the research efforts of WBE are concentrated in Europe. Originally, determining the population-wide use or misuse of illicit or therapeutic drugs, pharmaceuticals and personal care products, tobacco and alcohol use, pesticide exposure, ${ }^{5}$ genetic biomarkers, ${ }^{6}$ etc. was the main target of WBE. Later, this concept gradually involved a broad array of other types of substances in wastewater, including virus particles. ${ }^{7}$ This evolution has led to the introduction of new analytical techniques, as, in the case of biological material, the analysis of DNA and RNA fragments by polymerase chain reaction (PCR) that is in many aspects irreplaceable. Recently and as a most relevant example due to the wide literature on the topic, COVID-19 has been detected in sewage, which supports the idea of using WBE to reveal the scale of COVID-19 outbreak. ${ }^{8-12}$ Conventional reverse transcription (RT)-PCR and upgraded PCR devices, like digital (d)PCR or droplet digital (dd)PCR, have been reported not only for DNA but also for the RNA, as well. The main advantage of using dPCR or ddPCR is the increasing sensitivity of at least 1 order of magnitude compared to that with PCR. ${ }^{9,10}$ Although PCR has become so prevalent for the determination of viruses, the complexity of wastewater means that it still suffers from many unresolved problems, such as proper extraction, cleanup, detection, and quantification of the genetic material. MS may be a good alternative to provide complementary information and help to overcome the problems.

With regard to the application of WBE for large molecules, the literature is rather scarce. The potential relevance for WBE of the

Received: August 12, 2021

Accepted: October 22, 2021

Published: November 8, 2021

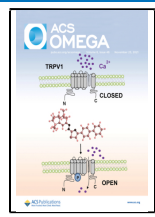



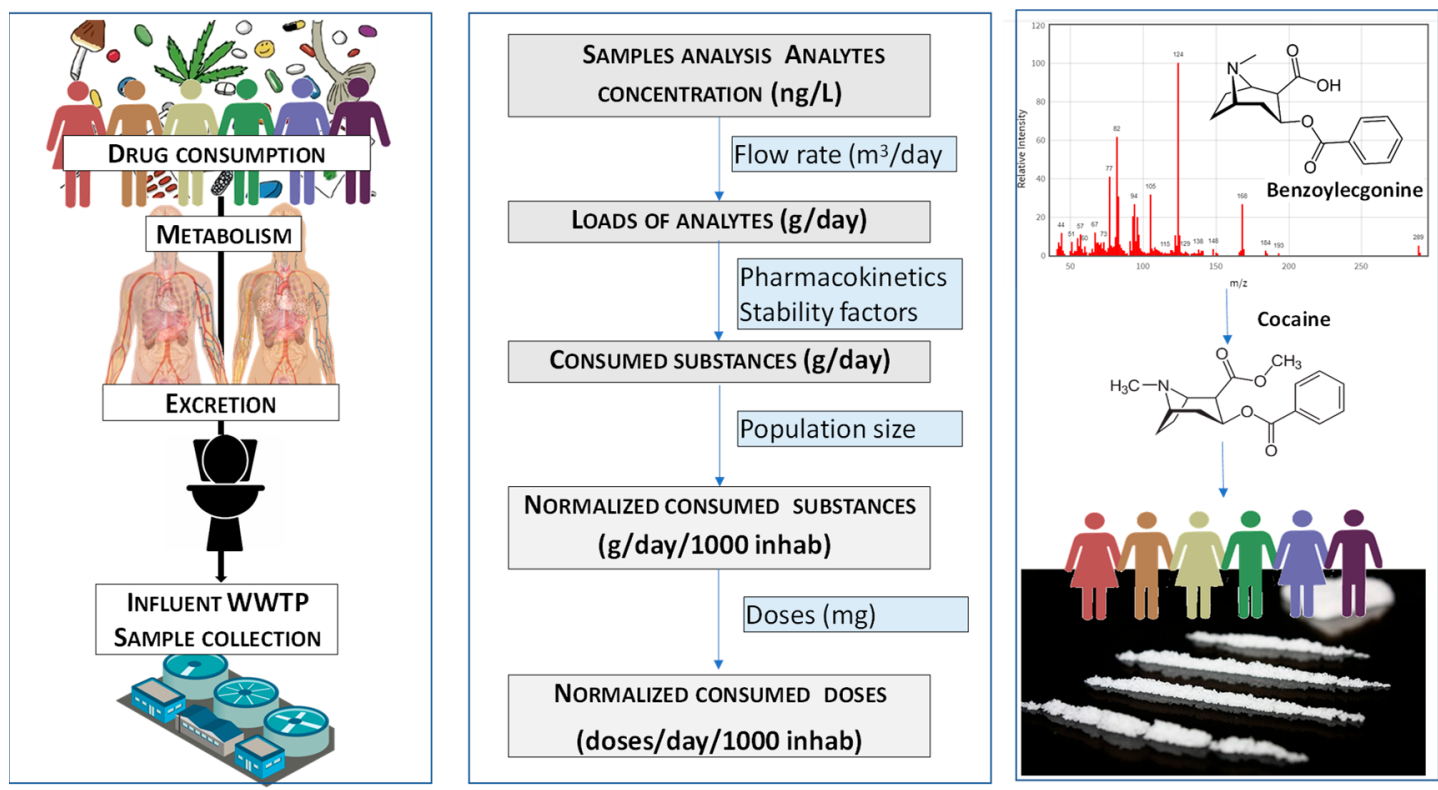

Figure 1. Scheme of the WBE for the determination of illicit drug consumption.

Table 1. Use of Some Biomarkers Identified in HBM for WBE Using LC-MS

\begin{tabular}{|c|c|c|}
\hline compounds & biomarkers & ref \\
\hline \multicolumn{3}{|l|}{ consumption of addictive substances } \\
\hline \multicolumn{3}{|l|}{ illicit drugs } \\
\hline cocainics & human metabolites (mostly benzoylecgonine) & $5,16,17,19,20$ \\
\hline opioids & human metabolites and parent compounds & $5,16,17,19,20$ \\
\hline cannabis & human metabolites (mostly tetrahydrocannabinoic acid) & $5,16,17,19,20$ \\
\hline amphetaminics & parent compounds & $5,16,17,19,20$ \\
\hline tobacco & $\begin{array}{l}\text { parent compound (nicotine) and human metabolites (cotinine, } 3^{\prime} \text { - } \\
\text { hydroxycotinine, anabasine, anatabine) }\end{array}$ & $5,16,17,19,20$ \\
\hline alcohol & human metabolites (ethyl sulfate) & $5,16,17,19,20$ \\
\hline caffeine & parent compound (caffeine) and human metabolites (1,7-dimethyluric acid) & $5,16,17,19,20$ \\
\hline new psychoactive compounds & mostly parent compounds & $5,16,17,19,20$ \\
\hline \multicolumn{3}{|l|}{ consumption of pharmaceuticals } \\
\hline $\begin{array}{l}\text { pharmaceuticals (nonsteroidal anti-inflammatory drugs, } \\
\text { antibiotics, anticancerigens, etc.) }\end{array}$ & $\begin{array}{l}\text { mostly parent compounds and transformation products, human metabolites in } \\
\text { very few cases }\end{array}$ & $5,16,17,19,20$ \\
\hline \multicolumn{3}{|l|}{ food consumption } \\
\hline artificial sweeteners & as parent compounds (they are neither metabolized nor degraded) & $5,16,17,19,20$ \\
\hline \multicolumn{3}{|l|}{ exposure to contaminants } \\
\hline organophosphorus flame retardants & human metabolites (hydroxylated) & $5,16,17,19,20$ \\
\hline plasticizers and phthalates & human metabolites & $5,16,17,19,20$ \\
\hline $\begin{array}{l}\text { pesticides (triazines, organophosphorus, organochlorine, and } \\
\text { pyrethroids) }\end{array}$ & human metabolites (hydroxylated, dealkyl, and acids) & $\begin{array}{l}5,16,17,18,19 \\
20,22\end{array}$ \\
\hline mycotoxins & specific metabolites & $5,16,17,19,20$ \\
\hline \multicolumn{3}{|l|}{ prevalence of disease } \\
\hline hepatitis B & lamivuline (pharmaceutical) & $5,16,17,19,20$ \\
\hline stress & $\begin{array}{l}\text { 8-iso-prostaglandin } \mathrm{F} 2 \alpha \text {, its metabolite dinor-11 } \beta \text {-prostaglandin } \mathrm{F} 2 \alpha \text {, and } \\
\text { prostaglandin } \mathrm{E} 2\end{array}$ & $\begin{array}{l}5,16,17,19,20 \\
21\end{array}$ \\
\hline diabetes & metformin (pharmaceutical) & $\begin{array}{l}5,16,17,19,20 \\
21\end{array}$ \\
\hline gout & oxyallopurinol (metabolite of a pharmaceutical allopurinol) & $\begin{array}{l}5,16,17,19,20 \\
21\end{array}$ \\
\hline
\end{tabular}

human proteins present in sewage waters was already stated by Rice and Kasprzyk-Horden. ${ }^{13}$ This approach appeared as a new paradigm for public health assessment, although no experimental work was performed to demonstrate with a case study the feasibility of WBE for large molecules. Only recently, our work $^{14,15}$ demonstrated that valuable information on large molecules can be achieved by analyzing wastewater treatment plant (WWTP) influent and effluent.
In this mini-review, we bring together the recent progress of WBE using MS targeted to small molecules, where most of the literature has been already published, and to large molecules, with very few papers reporting proteins and peptides as biomarkers of exposure. Ideas for future monitoring of viral proteins such as SARS-CoV-2 in WBE are outlined by incorporating the experience from LC-MS in clinical studies to determine proteins and peptides. We believe that WBE MS is 


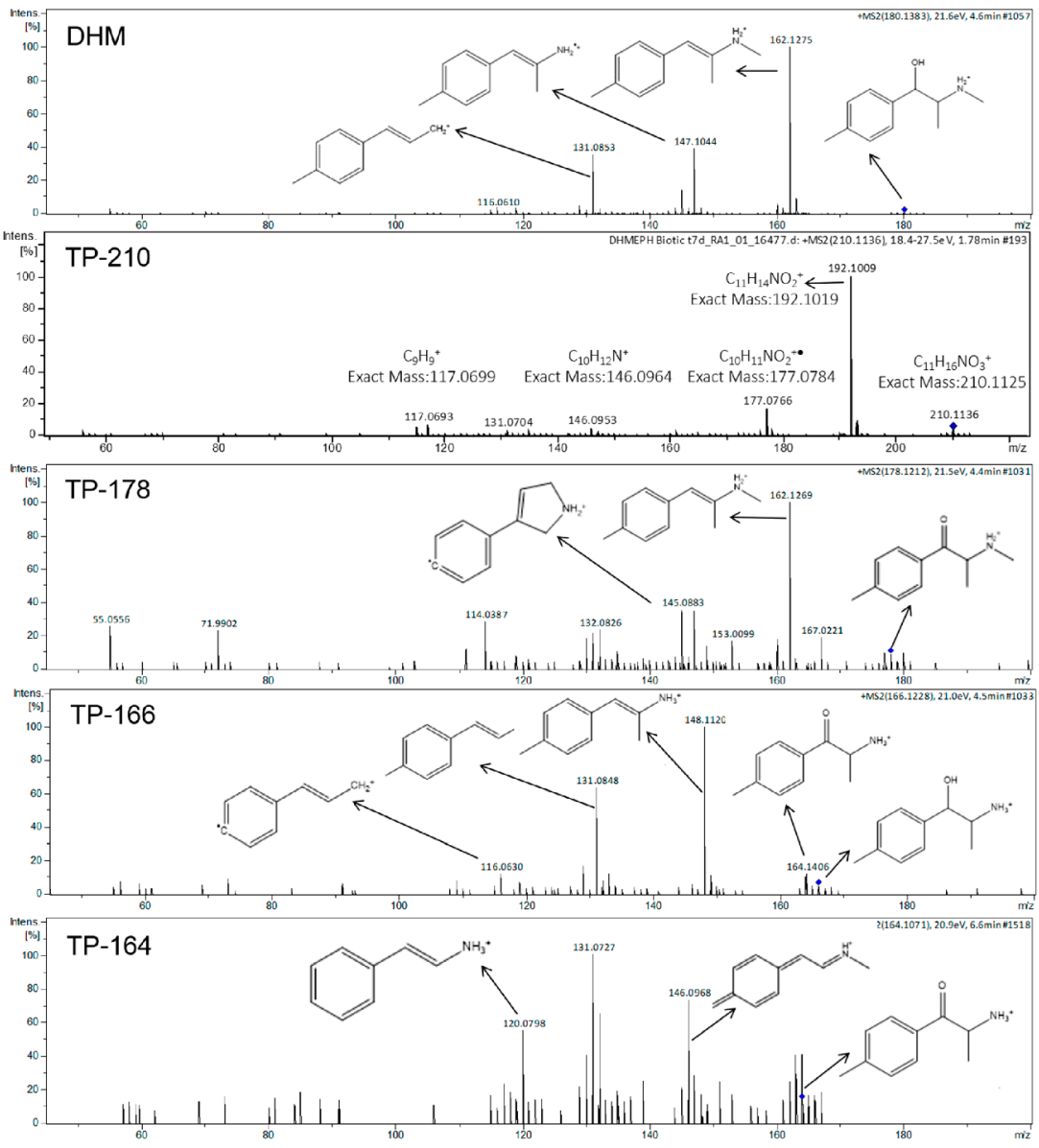

Figure 2. MS/MS spectra and fragmentation pattern of DHM, TP-210, TP-166, TP-178, and TP-164. Reprinted with permission from ref 24. Licensee MDPI, Basel, Switzerland. Creative Commons Attribution (CC BY) license (http://creativecommons.org/licenses/by/4.0/).

a useful approach rather complementary to PCR methodologies by reporting more accurate information on the virus-specific peptides.

\section{MS FOR SMALL MOLECULES AS BIOMARKERS}

The main challenge of WBE to provide a fingerprint of different aspects of health, habits, well-being, and lifestyle of a community is the selection of specific biomarkers of human metabolism, excreted in sufficient and stable quantities in wastewater. Normally, the identification of these biomarkers is based on an in-depth search of human biomonitoring (HBM) reports that identify candidates. Several interesting reviews compile extensive lists of many of these potential biomarkers for WBE. ${ }^{5,16-21}$ Likewise, liquid chromatography-tandem mass spectrometry (LC-MS/MS) using triple quadrupole (QqQ) or linear quadrupole ion trap (QTRAP) has emerged as a powerful technique for the simultaneous detection of multiple biomarkers in wastewater, providing critical information about their occurrence. In most of these studies, LC-MS/MS is used as targeted analysis, in which the biomarkers are selected "a priori" and other related products cannot be detected because only specific transitions are monitored. The use of this type of analysis ensures maximum sensitivity, which is a crucial aspect in these analyses. In any case, MS-based methods can successfully detect in wastewater biomarkers listed in Table 1. However, biomarkers selected through the study of the HBM are broader, and it is not clear whether several of these biomarkers are suitable for WBE or not. The final use of these biomarkers in wastewater will depend on their prevalence in wastewater (they must be detected) and their stability (their excretion cannot be evaluated if they are not stable). More information and numerous "in situ" studies are therefore required. Table 1 reflects how in many cases substances used are not exclusive of humans (parent compounds and/or degradation products that can come from other sources). In those cases, exposure is more difficult to assess, being still an ongoing study. As an interesting example, Rousis ${ }^{22}$ proposed the urinary factor to deal with this problem, although this factor still needs further improvement to its application.

It is also important to note that the choice of MS instrument depends on the purpose of the analysis. For example, a LCQqQ-MS/MS is often the choice for quantitative analysis of most of the small molecules for WBE as mentioned above. However, high-resolution mass spectrometry (HRMS), using quadrupole time-of-flight (QqTOF) or Orbitrap, could be a best option to directly identify human biomarkers in wastewater opening a new avenue in WBE. Several biomarkers have also been identified due to intense research on these HRMS systems. One difficulty is that wastewater contains thousands of compounds, and the biomarkers of interest may not be in the majority. The simplest solution is to use what is known as suspected screening or wide screening, which involves building a database with those compounds recognized in the literature or in other databases facilitating the identification of compounds. $^{21,23,24}$ Few examples of nontarget analysis have also been reported in succeeding with the identification of unknown 
Raw Data

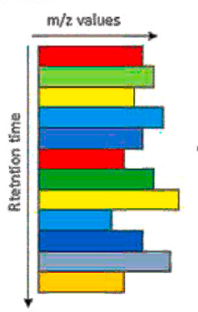

ROI procedure
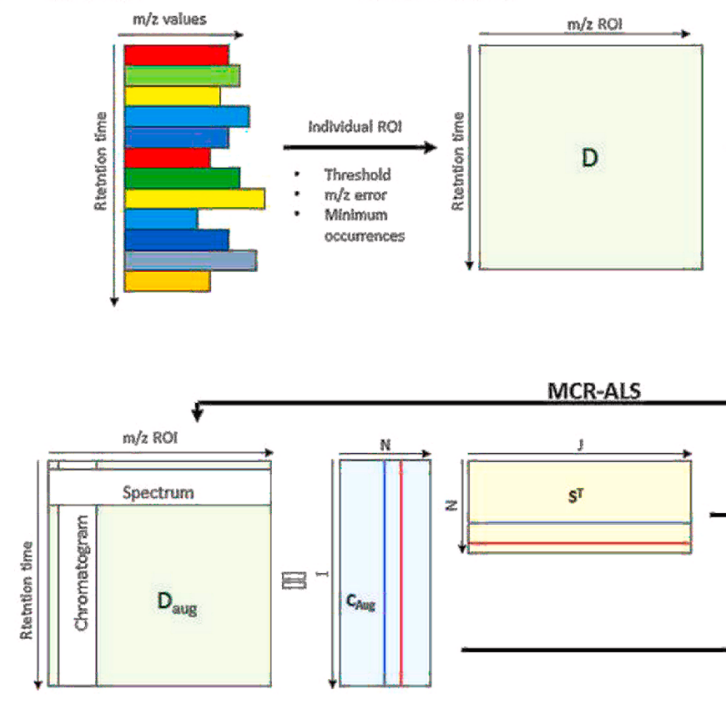
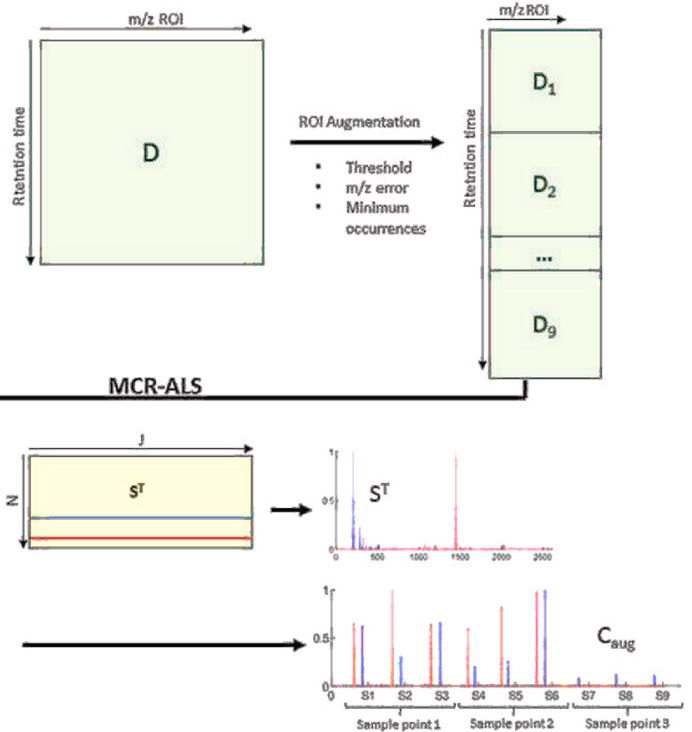

Figure 3. ROIMCR workflow. Reprinted with permission from ref 15 under a Creative Commons Attribution-Noncommercial 4.0 Unported License. Copyright 2021 Elsevier.

compounds due to the possibility of sharing the most probable empirical formula and the fragmentation pattern to several Internet available databases to recognize the unknown compound recorded by MS for identifying if it is a potential biomarker. $^{25,26}$ The use of in silico tools (mostly retention time, fragmentation, biocatalysis, biodegradation, metabolism, or transformation products prediction models) has also propelled the discovery of biomarkers from the raw MS data. ${ }^{23,25}$ Interestingly, the fate of new psychoactive substances (NPS) and their transformation products in WWTPs is not wellunderstood. Kinyua et al. ${ }^{24}$ set up batch reactors seeded with activated sludge to evaluate biotic, abiotic, and sorption losses of $p$-methoxymethylamphetamine (PMMA) and dihydromephedrone (DHM) and identify transformation products using some of these simulation models. These tools confirm that main reactions were $\mathrm{O}$ - and $\mathrm{N}$-demethylation, oxidation, and hydroxylation. Figure 2 illustrates the identification of several DHM transformation products and their fragmentation pattern. Evaluation of wastewater profiles or fingerprinting by MS has also been demonstrated to be useful in biomarker identification. This approach usually requires the application of bioinformatics that support clustering classification to organize ionic signals with common characteristics into different groups, the estimation of ionic signal intensity in a space, and the application of complex multivariant statistics and development of predictive models. This format is still in its infancy regarding WBE. Although not yet widely applied within the field of WBE, the use of HRMS offers a range of new possibilities to further expand the detection of small molecules that act as useful biomarkers in wastewater. $^{24,27}$

\section{MS FOR LARGE MOLECULES AS BIOMARKERS}

The identification of proteins in urban wastewater have been proposed as a logical continuation of the intense search for biomarkers that started recently. Proteins can be an excellent indicator of prevalent diseases in a population. However, the transition from theory to practice is taking a long time.

Proteins together with biomarker composition in sewage can reflect the surrounding human activities (e.g., industry, agriculture, and pest control) and the health status of populations based on WBE. Biomarkers might be found in the soluble part of water, but proteins could be expected in particulate matter because many proteins travel in water media by attaching on the surface of particles and bacteria. MS approaches based on LC-Orbitrap-MS and matrix-assisted laser desorption/ionization (MALDI)-TOF could be feasible for rapid detection and routine monitoring of protein characterization. ${ }^{14,15}$ This was the first step toward the characterization of human protein biomarkers in sewage waters. Carrascal et al. ${ }^{14}$ demonstrated the presence in urban sewage waters of proteins from diverse origins, including human proteins such as uromodulin, $\alpha$-amylase, and S100A8, which have been proposed as health markers associated with renal function and stressrelated changes. ${ }^{28}$ However, one of the difficulties that is needed to overcome is the high prevalence of bacterial proteins in front of the others.

Due to the large number of data recorded, the bioinformatic treatment to recognize the complex pattern of the omics already mentioned for small molecules becomes crucial. Interestingly, Perez-Lopez et al. ${ }^{15}$ applied a recent metabolomics methodology named the regions of interest-multivariate curve resolution (ROIMCR) to proteomics. This methodology combines the searching of the regions of interest (ROI) and the multivariate curve resolution-alternating least squares (MCR-ALS) for the resolution of the constituents of the analyzed samples. Figure 3 displays the workflow of the ROIMCR methodology.

Both papers ${ }^{14,15}$ provide additional information on the samples related to human peptide biomarkers to a variety of characteristic peptides of biological species such as rat, mouse, cattle, chicken, as well as to many bacteria. To the best of our knowledge, these are the first nontarget proteomic studies with the identification of a variety of proteins at the different stages of the WWTP. It is well-known that WWTPs contain a comprehensive list of large molecules, e.g., proteins that are biomarkers of exposure. Among proteins of interest, it has been recently pointed out that the detection of viral proteins will be a valuable tool to follow pandemic outbreaks, e.g., COVID-19, but 
Table 2. Comparison of RT-PCR versus Amplicon and Viral Peptide Detection for SARS-CoV-2 Diagnosis ${ }^{a}$ (Reprinted with Permission from Reference 30, Copyright 2021 Elsevier

\begin{tabular}{|c|c|c|c|c|}
\hline step/parameter & RT-PCR detection & DNA amplicon detection by MS & $\begin{array}{l}\text { viral peptide detection by } \\
\text { MALDI-MS }\end{array}$ & $\begin{array}{c}\text { viral peptide sequencing by LC- } \\
\text { ESI-MS/MS }\end{array}$ \\
\hline $\begin{array}{l}\text { viral component } \\
\text { recovery }\end{array}$ & RNA & RNA & protein & protein \\
\hline recovery time & minutes & minutes & $1-2 \mathrm{~h}$ & $1-2 \mathrm{~h}$ \\
\hline preanalysis steps & $\begin{array}{l}\text { reverse transcription, denaturation, } \\
\text { annealing, amplification }{ }^{b}\end{array}$ & $\begin{array}{l}\text { reverse transcription, denaturation, } \\
\text { annealing, amplification }{ }^{b}\end{array}$ & $\begin{array}{l}\text { proteolytic digestion with/ } \\
\text { without reduction/alkylation }\end{array}$ & $\begin{array}{l}\text { proteolytic digestion with/ } \\
\text { without reduction/alkylation }\end{array}$ \\
\hline preanalysis time & $30 \mathrm{~min}$ & $30 \mathrm{~min}$ & $4-14 h^{c}$ & $4-14 h^{c}$ \\
\hline detection time & $2-4 \mathrm{~h}$ & few minutes & few minutes & $30 \mathrm{~min}$ to $1 \mathrm{~h}$ \\
\hline $\begin{array}{l}\text { detection limit } \\
\text { (copies) }\end{array}$ & $\sim 10$ & $>10-10^{2}$ & $>10^{5 d}$ & $10^{5}-10^{6}$ \\
\hline $\begin{array}{l}\text { reliability/ } \\
\text { confidence }\end{array}$ & up to $95 \%$ & $\begin{array}{l}\text { high (with multiple amplicons } \\
\text { detected) }\end{array}$ & $\begin{array}{l}\text { high (with multiple peptides } \\
\text { detected) }\end{array}$ & $\begin{array}{l}\text { high (with multiple peptides } \\
\text { sequenced) }\end{array}$ \\
\hline $\begin{array}{l}\text { analysis cost/ } \\
\text { sample (USD) }\end{array}$ & $\$ 10$ & $\$ 10-50$ & $\$ 100$ & $\$ 250$ \\
\hline $\begin{array}{l}\text { instrument cost } \\
\text { (USD) }\end{array}$ & $\$ 20 \mathrm{~K}+$ & $\$ 100 \mathrm{~K}+$ & $\$ 100-1000 \mathrm{~K}+$ & $\$ 250-500 \mathrm{~K}+$ \\
\hline
\end{tabular}

${ }^{a}$ All times and figures are approximate only and depend on specific protocols and equipment employed. ${ }^{b}$ According to real-time RT-PCR detection of SARS-CoV-2 protocol, Institute Pasteur, Paris (https://www.who.int/docs/default-source/coronaviruse/real-time-rt-pcr-assays-for-thedetection-of-sars-cov-2-institut-pasteur-paris.pdf). ${ }^{c}$ Improved using immobilized enzyme digestion to $1-2 \mathrm{~h}$. ${ }^{d}$ Improved by $1-2$ orders of magnitude with selected ion monitoring.

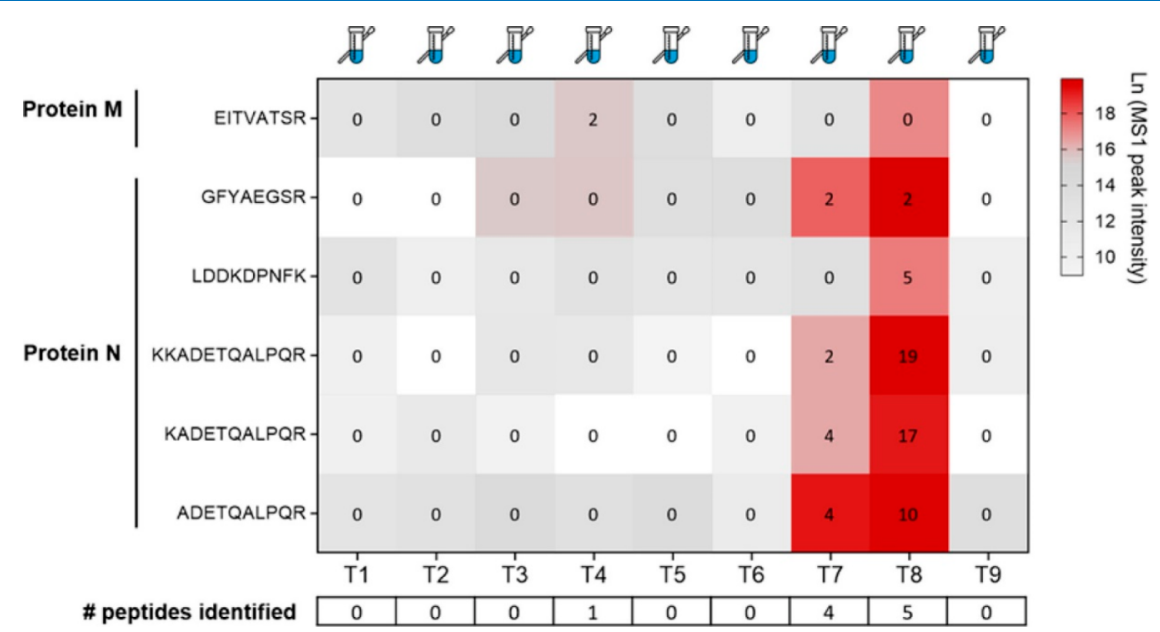

Figure 4. Heatmap of peptide intensities in the clinical nasopharyngeal swabs. Cell color corresponds to MS1 peak area, red being the highest and white the lowest. Numbered cells correspond to the number of PSMs from the MS/MS search that identified the peptide; cells with zero values mean that no MS/MS spectra were attributed to the peptide in that sample (at FDR 1\%). The number of identified peptides in each sample is indicated on the bottom of the figure. Patients were numbered from "swab T1" to "swab T9". Reprinted from ref 31 under a Creative Commons AttributionNoncommercial 4.0 Unported License. Copyright 2020 American Chemical Society.

at present, the MS detection limits are not sensitive enough to compete with PCR tools.

\section{MS IN THE AREA OF COVID-19}

4.1. SARS-CoV-2 Protein Structure. SARS-CoV-2 proteins can be categorized into two major groups: structural and nonstructural proteins. Although nonstructural proteins (e.g., enzymes and transcription factors needed for replication) are encoded by the virus, they can only be found in the infected host cells. These proteins are neither incorporated into the virion nor highly expressed and, thus, are less likely to be detected. The four structural proteins present in the virion particle are known as spike (S), envelope (E), membrane (M), and nucleocapsid $(\mathrm{N})$. The $\mathrm{N}$ protein encapsulates and protects the RNA genome, and the $S, E$, and $M$ constitute the viral envelope. ${ }^{29}$ Previous data on SARS-CoV, with a structure similar to that of SARS-CoV-2, indicate that the number of copies of $\mathrm{E}, \mathrm{M}$, and $\mathrm{N}$ proteins is much higher than that of $S$, but $E$ and $M$ are relatively short proteins, tightly bound to the membrane, and therefore difficult to extract and detect. ${ }^{29}$ These proteins could be found in wastewater.

4.2. Analytical Determinations (LC/Electrospray MS/ MS) and MALDI-TOF MS of SARS-CoV-2. In this section of MS in the area of COVID-19, we show the possibility of using WBE MS for SARS-CoV-2 determination. In this respect, it is worth indicating that, although MS has been already used to determine viral proteins and peptides such as SARS-CoV-2 and other virus in clinical studies, its use in WBE is still pending.

There are few examples from the literature on the use of LCelectrospray (ESI)-MS/MS and MALDI-TOF-MS for SARS$\mathrm{CoV}-2$ proteins and peptides. It needs to be addressed that, until now, none of the samples analyzed were collected into WWTP, and all of them corresponded to human/clinical samples. The application of WBE MS of viral proteins and peptides is still a utopia. Lack of sensitivity of the current instrumentation and/or 
complexity of the wastewater samples to be analyzed are the main constraints to its implementation.

An excellent review paper recently published ${ }^{30}$ explored many and varied MS responses to SARS-CoV-2. RT-PCR is the most prevalent molecular-based surveillance approach. However, it has several drawbacks such as the high number of false positives that can be palliated by the complementary information provided by MS. Table 2 compares RNA detection by RTPCR versus DNA amplicon detection by $\mathrm{MS}$, viral peptide detection by MALDI-TOF, and viral peptide sequencing by LC-ESI-MS/MS. The detection threshold for RNA by RTPCR requires no more than 10 copies, 100 copies for DNA-MS, and 100000 copies for MALDI-MS and LC-ESI-MS/MS. This illustrates well the different sensitivities of different techniques and the need to apply PCR to WBE of viruses. In this field, the improvements already envisaged in MS, such as single cell MS, ion mobility MS, imaging MS, or the combination of MS with nano- or micro-LC, as well as the constantly increasing sensitivity of the new instruments, may soon transform utopia into reality.

In this sense, Gouveai et al. ${ }^{31}$ already reported a proof-ofconcept study by testing the potential of LC-MS/MS-based methods for identifying SARS-CoV-2 peptides in nasopharyngeal swabs. With a 20 min MS acquisition window, several virus-specific peptides that allowed proteotyping the virus were identified and quantified in simulated and clinical swabs from COVID-19 patients. The peptides ADETQALPQR (and its variant forms) and GFYAQGSR from the nucleocapsid protein were detected. These peptides are of utmost interest to develop quick and robust targeted assays for identifying the virus. To confirm this, the heatmap in Figure 4 displays the MS1 peak areas, the number of peptide-to-spectrum matches (PSMs) attributed to each peptide in each sample, the number of viral peptides identified in each sample, and the result from the PCR testing performed on the same sample. The authors recognized that it in a second step a greater number of clinical specimens must be tested to validate the usefulness and limits of detection of these peptides. Another point that is relevant for the method's validation is to calculate the percentage of confirmation rate of positive PCR results with these identified peptides that can be used as tracers for SARS-CoV-2 unequivocal identification. Would it be possible to use a similar approach soon for WBE? It would be excellent!

In other study, Sanda et al. ${ }^{32}$ reported the analysis of the sitespecific glycoforms with focus on the resolution of structural motifs of the identified O- and N-glycopeptides by LC-MS/MS with higher energy collisional dissociation fragmentation and modulated normalized collision. This study on the SARS-CoV S protein identified nine occupied O-glycopeptides and $17 \mathrm{~N}$ glycopeptides in the $\mathrm{S}$ proteins produced in human embryonic kidney (HEK) 293 cells.

Although LC-ESI-MS/MS is the method of choice for peptide quantitation. MALDI-TOF MS-based peptidome analysis can be applied as a fast, high-throughput, low-cost, and easy-to-use technique. This approach has been successfully used in clinical applications, including microorganism identification. Yan et al. ${ }^{33}$ collected serum samples of 146 COVID-19 patients with mild, typical, severe, and critical symptoms and 152 control individuals, including non-COVID-19 patients with fever/cough symptoms, tuberculosis patients, and healthy controls, and analyzed them by MALDI-TOF-MS. The results outlined $25 \mathrm{MS}$ peaks showing statistically significant differences between COVID-19 patients and control individuals. Using various machine-learning methods, a model was constructed with the 25 peaks showing high accuracy (99\%) for the identification of COVID-19 patients with a sensitivity of $98 \%$ and specificity of $100 \%$ on a test cohort (100 samples) independent from the samples used for model generation and feature selection. This accurate and rapid method provides a powerful tool for high-throughput screening and surveillance of COVID-19.

These few examples of clinical applications highlight the interest in developing MS techniques. This pioneering work can serve as a basis for new developments to apply MS to WBE and to obtain the additional information that MS can offer as a complement to PCR data.

\section{CONCLUSIONS}

Currently, WBE is involved in going one step further by increasing biomarker fingerprinting of the characteristics and health of populations. The identification of small molecules used as biomarkers is linked to the search of HBM studies and, on the other hand, to the advances in MS. In the latter, the introduction of HRMS and the improvement of raw data processing, identification systems, and applied bioinformatics has opened an important door to the discovery of new useful biomarkers directly in wastewater. However, this aspect of WBE is not yet resolved, and the lack of human-specific metabolites for some compounds and additional sources of transformation products needs to be addressed. Solving these problems can be somewhat time-consuming due to the complexity of wastewater. This leads us to ask a question that can be applied to the rest of the conclusions: Shall we need to increase/cleanup/sample preparation of the WWTP samples? There are many pros and cons to any of the answers that can be given and should be carefully evaluated on a case-by-case basis.

Recently, there is an emerging interest in complementing the metabolite profile of biomarkers determined in wastewater with proteomics, considering that proteins can be a good indicator of prevalent diseases in the population. Although the studies are still scarce, WBE of large molecules using MS has a lot of possibilities. In this field, the use of HRMS with nontarget approaches and bioinformatics data processing are sublimated. Problems in the application of proteomics to wastewater remain, such as the prevalence of the bacterial proteome versus human proteome, which makes the identification of the latter difficult. Nevertheless, despite the limited number of studies that exist, several proteins of human origin have been identified that may be related to renal function and stress. This is the first step. It is to be hoped that soon these studies will multiply and will be able to gradually eliminate their difficulties. It can be safely predicted that the role of intelligent bioinformatics systems will be very important. Common proteins and peptides related to humans will be soon identified, and hopefully soon proteins and peptides from SARS-CoV-2 and other viruses will also play an important role in the correct identification.

Virus identification is the only field of WBE where MS is not prevalent. However, although aspects such as sensitivity still need to be resolved, in clinical analysis, the identification of these proteins is a reality of great help in diagnosis. There are several questions raised from the previous discussion:

Should we be able to find the specific peptides ADETQALPQR (and its variant forms) and GFYAQGSR from the nucleocapsid protein responsible of SARS-CoV-2 infection in WBE? This would always help to improve identification and why 
not? The future is always going a step forward, and this would be of help.

Do we need a more sensitive LC-MS/MS for SARS peptide specific detection in WWTP? Clearly yes, but the advances in MS do not stop. There are new emerging techniques in MS instrumentation, and sample handling strategies are quickly making comprehensive omics analyses of single cells feasible; ion mobility mass spectrometry and improved workflows in nontarget analysis are enhancing sensitivity to unexpected extremes.

Although MS advances augur well for the future with great expectations, one thing is crystal clear: LC-MS will be complementary to PCR infection, and the confirmation results obtained in WBE will need to be compared with those of PCR.

\section{AUTHOR INFORMATION}

\section{Corresponding Authors}

Yolanda Picó - Environmental and Food Safety Research Group-University of Valencia (SAMA-UV), Desertification Research Centre (CIDE), Joint Center CSIC-University of Valencia-Generalitat Valenciana, 46113 Moncada, Valencia, Spain; 이이이.org/0000-0002-9545-0965;

Email: yolanda.pico@uv.es

Damià Barceló - Water and Soil Quality Research Group, Department of Environmental Chemistry, IDAEA-CSIC, 08034 Barcelona, Spain; Catalan Institute for Water Research, ICRA - CERCA, Technological Park of the University of Girona, 17003 Girona, Spain; 이이이.org/0000-00028873-0491; Email: damia.barcelo@idaea.csic.es

Complete contact information is available at: https://pubs.acs.org/10.1021/acsomega.1c04362

\section{Notes}

The authors declare no competing financial interest.

\section{Biographies}

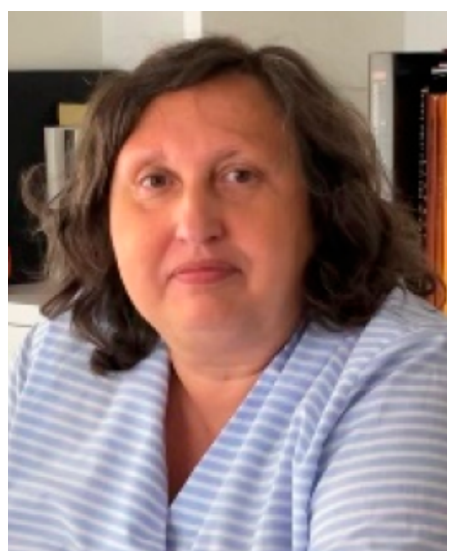

Yolanda Picó Yolanda Picó is Full Professor of Nutrition and Food Chemistry and Researcher at the Desertification Research Centre (CIDE) at the University of Valencia. She is the coordinator of the Food Safety and Environmental Research Group (SAMA-UV). Her scientific trajectory accumulates more than 30 years of experience in the fields of Environmental and Food Chemistry, developing analytical methods to contribute significantly to the improvement of the environment and determining the impact of climate change and human development in the presence of traditional and emerging contaminants. Along her career, she has published more than 300 articles included in SCI and more than 20 book chapters and is editor of five international books.

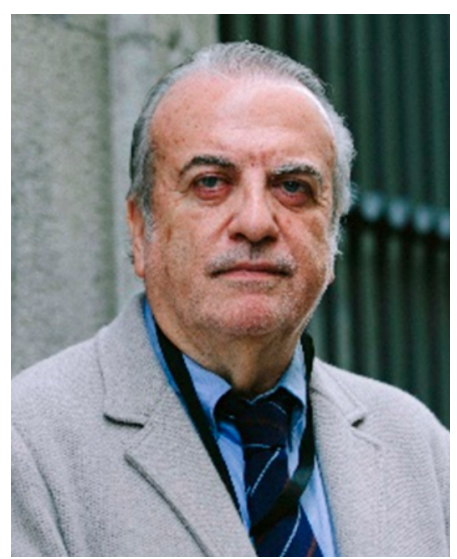

Damià Barceló is a Full Professor at IDAEA-CSIC, Barcelona, Spain, and since 2008, is the Director of the Catalan Institute for Water Research (ICRA-CERCA), Girona, Spain. He was recently awarded Doctor Honoris Causa by the University of Lleida, Spain and TalentGuest Professor at Zhejiang A\&F University (ZAFU), Hangzhou, China. His research falls into the field of water quality and wastewater treatment plants, in particular, on the analysis, fate, risk, and removal of emerging pollutants, microplastics, and large molecules such as protein/peptide biomarkers. Up until today he has supervised 67 Ph.D. students. Editorial activities started in the 1990s, being contributing editor of Trends in Analytical Chemistry (TrAC) and editor of the book series Comprehensive Analytical Chemistry, The Handbook of Environmental Chemistry and Advances In Chemical Pollution, Environmental Management and Protection. In 2012, he was appointed co-Editor-in-Chief of the Science of the Total Environment, in 2017, Editor-in-Chief of Current Opinion in Environmental Science and Health, and, in 2020, co-Editor-in-Chief of Case Studies of Chemical and Environmental Engineering, all three journals published by Elsevier.

\section{ACKNOWLEDGMENTS}

This work has been supported by Grant RTI2018-097158-BC31 funded by MCIN/AEI/ 10.13039/501100011033 and by "ERDF A way of making Europe", Grant PID2020-114065RBC22 funded by MCIN/ AEI/ 10.13039/501100011033 and project ANTROPOCEN@ (PROMETEO/2018/155) funded by Generalitat Valenciana.

\section{REFERENCES}

(1) Shimko, K. M.; Piatkowski, T.; Thomas, K. V.; Speers, N.; Brooker, L.; Tscharke, B. J.; O’Brien, J. W. Performance- and imageenhancing drug use in the community: use prevalence, user demographics and the potential role of wastewater-based epidemiology. J. Hazard. Mater. 2021, 419, 126340.

(2) Lorenzo, M.; Picó, Y. Wastewater-based epidemiology: current status and future prospects. Curr. Opin. Environ. Sci. Health 2019, 9, 77-84.

(3) Daughton, C. G. Monitoring wastewater for assessing community health: Sewage Chemical-Information Mining (SCIM). Sci. Total Environ. 2018, 619-620, 748-764.

(4) Daughton, C. G. Wastewater surveillance for population-wide Covid-19: The present and future. Sci. Total Environ. 2020, 736, 139631.

(5) Vitale, D.; Morales Suárez-Varela, M.; Picó, Y. Wastewater-based epidemiology, a tool to bridge biomarkers of exposure, contaminants, and human health. Curr. Opin. Environ. Sci. Health 2021, 20, 100229.

(6) Yang, Z.; Xu, G.; Reboud, J.; Kasprzyk-Hordern, B.; Cooper, J. M. Monitoring Genetic Population Biomarkers for Wastewater-Based Epidemiology. Anal. Chem. 2017, 89, 9941-9945. 
(7) Sims, N.; Kasprzyk-Hordern, B. Future perspectives of wastewater-based epidemiology: Monitoring infectious disease spread and resistance to the community level. Environ. Int. 2020, 139, 105689.

(8) Buonerba, A.; Corpuz, M. V. A.; Ballesteros, F.; Choo, K.-H.; Hasan, S. W.; Korshin, G. V.; Belgiorno, V.; Barceló, D.; Naddeo, V. Coronavirus in water media: Analysis, fate, disinfection and epidemiological applications. J. Hazard. Mater. 2021, 415, 125580.

(9) Kumar, M.; Dhangar, K.; Thakur, A. K.; Ram, B.; Chaminda, T.; Sharma, P.; Kumar, A.; Raval, N.; Srivastava, V.; Rinklebe, J.; Kuroda, K.; Sonne, C.; Barcelo, D. Antidrug resistance in the Indian ambient waters of Ahmedabad during the COVID-19 pandemic. J. Hazard. Mater. 2021, 416, 126125.

(10) Barceló, D. Wastewater-Based Epidemiology to monitor COVID-19 outbreak: Present and future diagnostic methods to be in your radar. Case Stud. Chem. Environ. Eng. 2020, 2, 100042

(11) Wu, J.; Wang, Z.; Lin, Y.; Zhang, L.; Chen, J.; Li, P.; Liu, W.; Wang, Y.; Yao, C.; Yang, K. Technical framework for wastewater-based epidemiology of SARS-CoV-2. Sci. Total Environ. 2021, 791, 148271.

(12) Alygizakis, N.; Markou, A. N.; Rousis, N. I.; Galani, A.; Avgeris, M.; Adamopoulos, P. G.; Scorilas, A.; Lianidou, E. S.; Paraskevis, D.; Tsiodras, S.; Tsakris, A.; Dimopoulos, M.-A.; Thomaidis, N. S. Analytical methodologies for the detection of SARS-CoV-2 in wastewater: Protocols and future perspectives. TrAC, Trends Anal. Chem. 2021, 134, 116125.

(13) Rice, J.; Kasprzyk-Hordern, B. A new paradigm in public health assessment: Water fingerprinting for protein markers of public health using mass spectrometry. TrAC, Trends Anal. Chem. 2019, 119, 115621.

(14) Carrascal, M.; Abian, J.; Ginebreda, A.; Barceló, D. Discovery of large molecules as new biomarkers in wastewater using environmental proteomics and suitable polymer probes. Sci. Total Environ. 2020, 747, 141145.

(15) Perez-Lopez, C.; Ginebreda, A.; Carrascal, M.; Barcelò, D.; Abian, J.; Tauler, R. Non-target protein analysis of samples from wastewater treatment plants using the regions of interest-multivariate curve resolution (ROIMCR) chemometrics method. J. Environ. Chem. Eng. 2021, 9, 105752.

(16) Gracia-Lor, E.; Castiglioni, S.; Bade, R.; Been, F.; Castrignanò, E.; Covaci, A.; González-Mariño, I.; Hapeshi, E.; Kasprzyk-Hordern, B.; Kinyua, J.; Lai, F. Y.; Letzel, T.; Lopardo, L.; Meyer, M. R.; O’Brien, J.; Ramin, P.; Rousis, N. I.; Rydevik, A.; Ryu, Y.; Santos, M. M.; Senta, I.; Thomaidis, N. S.; Veloutsou, S.; Yang, Z.; Zuccato, E.; Bijlsma, L. Measuring biomarkers in wastewater as a new source of epidemiological information: Current state and future perspectives. Environ. Int. 2017, 99, 131-150.

(17) Choi, P. M.; Tscharke, B. J.; Donner, E.; O’Brien, J. W.; Grant, S. C.; Kaserzon, S. L.; Mackie, R.; O’Malley, E.; Crosbie, N. D.; Thomas, K. V.; Mueller, J. F. Wastewater-based epidemiology biomarkers: Past, present and future. TrAC, Trends Anal. Chem. 2018, 105, 453-469.

(18) Devault, D. A.; Karolak, S. Wastewater-based epidemiology approach to assess population exposure to pesticides: a review of a pesticide pharmacokinetic dataset. Environ. Sci. Pollut. Res. 2020, 1-8, $4695-4702$.

(19) Senta, I.; Rodriguez-Mozaz, S.; Corominas, L.; Petrovic, M. Wastewater-based epidemiology to assess human exposure to personal care and household products-a review of biomarkers, analytical methods, and applications. Trends Environ. Anal. Chem. 2020, 28, No. e00103.

(20) Gracia-Lor, E.; Rousis, N. I.; Hernández, F.; Zuccato, E.; Castiglioni, S. Wastewater-Based Epidemiology as a Novel Biomonitoring Tool to Evaluate Human Exposure to Pollutants. Environ. Sci. Technol. 2018, 52, 10224-10226.

(21) Andrés-Costa, M. J.; Andreu, V.; Picó, Y. Liquid chromatography-mass spectrometry as a tool for wastewater-based epidemiology: Assessing new psychoactive substances and other human biomarkers. TrAC, Trends Anal. Chem. 2017, 94, 21-38.

(22) Rousis, N. I.; Gracia-Lor, E.; Hernández, F.; Poretti, F.; Santos, M. M.; Zuccato, E.; Castiglioni, S. Wastewater-based epidemiology as a novel tool to evaluate human exposure to pesticides: Triazines and organophosphates as case studies. Sci. Total Environ. 2021, 793, 148618 .

(23) Boogaerts, T.; Quireyns, M.; Covaci, A.; De Loof, H.; van Nuijs, A. L. N. Analytical method for the simultaneous determination of a broad range of opioids in influent wastewater: Optimization, validation and applicability to monitor consumption patterns. Talanta 2021, 232, 122443.

(24) Kinyua, J.; Psoma, A. K.; Rousis, N. I.; Nika, M. C.; Covaci, A.; Van Nuijs, A. L. N.; Thomaidis, N. S. Investigation of biotransformation products of p-methoxymethylamphetamine and dihydromephedrone in wastewater by high-resolution mass spectrometry. Metabolites 2021, 11,66 .

(25) Andrés-Costa, M. J.; Andreu, V.; Picó, Y. Analysis of psychoactive substances in water by information dependent acquisition on a hybrid quadrupole time-of-flight mass spectrometer. J. Chromatogr. A 2016, $1461,98-106$.

(26) Kinyua, J.; Negreira, N.; McCall, A. K.; Boogaerts, T.; Ort, C.; Covaci, A.; van Nuijs, A. L. N. Investigating in-sewer transformation products formed from synthetic cathinones and phenethylamines using liquid chromatography coupled to quadrupole time-of-flight mass spectrometry. Sci. Total Environ. 2018, 634, 331-340.

(27) Diamanti, K.; Aalizadeh, R.; Alygizakis, N.; Galani, A.; Mardal, M.; Thomaidis, N. S. Wide-scope target and suspect screening methodologies to investigate the occurrence of new psychoactive substances in influent wastewater from Athens. Sci. Total Environ. 2019, $685,1058-1065$.

(28) Mattes, W.; Yang, X.; Orr, M. S.; Richter, P.; Mendrick, D. L. Biomarkers of Tobacco Smoke Exposure. In Advances in Clinical Chemistry; Makowski, G. S., Ed.; Elsevier, 2014; Chapter 1, Vol. 67, pp $1-45$.

(29) Nikolaev, E. N.; Indeykina, M. I.; Brzhozovskiy, A. G.; Bugrova, A. E.; Kononikhin, A. S.; Starodubtseva, N. L.; Petrotchenko, E. V.; Kovalev, G. I.; Borchers, C. H.; Sukhikh, G. T. Mass-Spectrometric Detection of SARS-CoV-2 Virus in Scrapings of the Epithelium of the Nasopharynx of Infected Patients via Nucleocapsid N Protein. J. Proteome Res. 2020, 19, 4393-4397.

(30) Griffin, J. H.; Downard, K. M. Mass spectrometry analytical responses to the SARS-CoV2 coronavirus in review. TrAC, Trends Anal. Chem. 2021, 142, 116328.

(31) Gouveia, D.; Miotello, G.; Gallais, F.; Gaillard, J. C.; Debroas, S.; Bellanger, L.; Lavigne, J. P.; Sotto, A.; Grenga, L.; Pible, O.; Armengaud, J. Proteotyping SARS-CoV-2 Virus from Nasopharyngeal Swabs: A Proof-of-Concept Focused on a 3 min Mass Spectrometry Window. J. Proteome Res. 2020, 19, 4407-4416.

(32) Sanda, M.; Morrison, L.; Goldman, R. N- and O-Glycosylation of the SARS-CoV-2 Spike Protein. Anal. Chem. 2021, 93, 2003-2009.

(33) Yan, L.; Yi, J.; Huang, C.; Zhang, J.; Fu, S.; Li, Z.; Lyu, Q.; Xu, Y.; Wang, K.; Yang, H.; Ma, Q.; Cui, X.; Qiao, L.; Sun, W.; Liao, P. Rapid Detection of COVID-19 Using MALDI-TOF-Based Serum Peptidome Profiling. Anal. Chem. 2021, 93, 4782-4787. 